\title{
Application value of nursing intervention combined with early nutritional support in preventive stoma reversion of low rectal cancer
}

\author{
XINMEI YE, DANDAN HE, JIE ZHAO, YUQING LEI, QIUQIONG YAO and HUI WANG \\ Department of Colorectal Anal Surgery, The Sixth Affiliated Hospital of Sun Yat-Sen University, \\ Guangzhou, Guangdong 510655, P.R. China
}

Received September 21, 2018; Accepted February 8, 2019

DOI: $10.3892 / \mathrm{ol} .2019 .10055$

\begin{abstract}
Application value of nursing intervention combined with early nutritional support treatment in preventive stoma reversion of low rectal cancer was explored. Ninety-two cases of low rectal cancer patients undergoing preventive stoma reversion from January 2014 to December 2016 were retrospectively analyzed. All the patients had closed fistula 3 months after neostomy. Forty-four cases with routine nursing care were the control group; 48 cases with early nutritional support and nursing intervention were the experimental group. Nutritional status, psychological status, incidence of adverse reactions, wound infection rate, number of shaped and regular defecation were compared in the two groups. The levels of albumin, prealbumin and serum total protein in the experimental group were significantly higher than those in the control group after operation $(\mathrm{P}<0.05)$; the levels of albumin in the two groups after operation were significantly lower than those before operation $(\mathrm{P}<0.001)$. The SAS and SDS scores in the experimental group were significantly lower than those in the control group after operation $(\mathrm{P}<0.001)$; the SAS and SDS scores in the two groups after operation were significantly lower than those before operation $(\mathrm{P}<0.001)$. The number of abdominal pain, abdominal distention, diarrhea, incision infection and abdominal infection in the experimental group were less than those in the control group $(\mathrm{P}<0.05)$. The number of shaped and regular defecation cases in the experimental group was more than that in the control group $(\mathrm{P}<0.05)$. Nursing intervention combined with early nutritional support can improve the nutritional status, psychological anxiety-depression of the patients undergoing preventive stoma reversion, decrease the
\end{abstract}

Correspondence to: Dr Hui Wang, Department of Colorectal Anal Surgery, The Sixth Affiliated Hospital of Sun Yat-Sen University, 26 Er'heng Road, Guangzhou, Guangdong 510655, P.R. China E-mail: hau2ry@163.com

Key words: low rectal cancer, early nutritional support, nursing intervention, preventive stoma reversion, anxiety-depression, wound infection incidence of adverse reactions, and wound infection rate. It can also increase the shaped and regular defecation cases and is helpful for the recovery of intestinal function.

\section{Introduction}

The proportion of rectal cancer in colorectal cancer is $56-70 \%$ (1). The death toll from rectal cancer has been increasing in recent years (2). In developing countries, the incidence ratio of middle and low rectal cancer, which is more difficult to treat in rectal cancer, accounts for $70-75 \%$ (3). Tumors with 3-8 cm distance from the lower margin to the anal margin are called low rectal cancer (4). At present, the patients with low rectal cancer are mostly treated with fistulation in clinic, which improves significantly the survival of patients. However, the changes of physical function can easily cause physiological and psychological effects on patients after operation (5).

Early enteral nutrition, that is, enteral nutrition given to patients 6-24 h after operation, can not only promote the recovery of postoperative intestinal function, but also reduce the incidence of related complications, accelerate the postoperative recovery, shorten the length of hospital stay and reduce economic losses for patients $(6,7)$. Nursing intervention can effectively relieve the anxiety after preventive stoma reversion, help the patients and their families to improve their self-care ability, and can effectively improve the postoperative recovery of patients $(8,9)$. However, early enteral nutritional support combined with nursing intervention is rarely used in preventive stoma reversion.

In this study, medical records of 92 patients with low rectal cancer undergoing preventive stoma reversion were retrospectively analyzed to explore the application value of nursing intervention combined with early nutritional support treatment in preventive stoma reversion of low rectal cancer.

\section{Materials and methods}

General information. Ninety-two cases of low rectal cancer patients undergoing preventive stoma reversion from January 2014 to December 2016 in the Sixth Affiliated Hospital of Sun Yat-Sen University (Guangzhou, China) were 
Table I. General information [n (\%)].

\begin{tabular}{|c|c|c|c|c|}
\hline \multirow[b]{2}{*}{ Factors } & \multicolumn{2}{|c|}{ Groups } & \multirow[b]{2}{*}{$\mathrm{t} / \chi^{2}$ value } & \multirow[b]{2}{*}{ P-value } \\
\hline & Experimental $(n=48)$ & Control $(n=44)$ & & \\
\hline Age (years) & $60.24 \pm 9.46$ & $59.12 \pm 10.73$ & 0.532 & 0.596 \\
\hline Sex & & & 0.565 & 0.519 \\
\hline Male & $32(66.67)$ & $26(59.09)$ & & \\
\hline Female & $16(33.33)$ & $18(40.91)$ & & \\
\hline Distance from tumor to anal margin $(\mathrm{cm})$ & $5.46 \pm 1.43$ & $5.52 \pm 1.69$ & 0.184 & 0.854 \\
\hline $\mathrm{BMI}\left(\mathrm{kg} / \mathrm{m}^{2}\right)$ & $24.14 \pm 1.53$ & $23.61 \pm 1.65$ & 1.599 & 0.113 \\
\hline Blood sugar value (mmol/l) & $4.78 \pm 0.56$ & $4.89 \pm 0.64$ & 0.879 & 0.382 \\
\hline Hemoglobin $(\mathrm{g} / \mathrm{l})$ & $143.59 \pm 4.15$ & $142.86 \pm 4.37$ & 0.822 & 0.413 \\
\hline Long-term smoking & & & 0.341 & 0.675 \\
\hline Yes & $28(58.33)$ & $23(52.27)$ & & \\
\hline No & $20(41.67)$ & $21(47.73)$ & & \\
\hline Long-term drinking & & & 0.207 & 0.680 \\
\hline Yes & 23 & 19 & & \\
\hline No & 25 & 25 & & \\
\hline
\end{tabular}

Table II. Comparison of nutritional status.

\begin{tabular}{|c|c|c|c|c|c|}
\hline \multirow[b]{2}{*}{ Index } & \multicolumn{2}{|c|}{ Groups } & \multirow[b]{2}{*}{ Control $(n=44)$} & \multirow[b]{2}{*}{$t$ value } & \multirow[b]{2}{*}{ P-value } \\
\hline & Time & Experimental $(\mathrm{n}=48)$ & & & \\
\hline \multirow[t]{4}{*}{ Albumin (g/l) } & Before operation & $36.46 \pm 3.11$ & $37.52 \pm 2.84$ & 1.702 & 0.092 \\
\hline & After operation & $34.12 \pm 3.08$ & $32.31 \pm 2.47$ & 3.092 & 0.003 \\
\hline & $\mathrm{t}$ value & 3.704 & 9.182 & & \\
\hline & P-value & $<0.001$ & $<0.001$ & & \\
\hline \multirow[t]{4}{*}{ Prealbumin (g/l) } & Before operation & $285.24 \pm 16.44$ & $287.91 \pm 18.32$ & 0.737 & 0.463 \\
\hline & After operation & $282.62 \pm 19.57$ & $271.13 \pm 20.13$ & 2.775 & 0.007 \\
\hline & t value & 0.710 & 4.089 & & \\
\hline & P-value & 0.479 & $<0.001$ & & \\
\hline \multirow{4}{*}{$\begin{array}{l}\text { Serum total } \\
\text { protein }(\mathrm{g} / \mathrm{l})\end{array}$} & Before operation & $60.23 \pm 3.86$ & $60.63 \pm 3.34$ & 0.529 & 0.598 \\
\hline & After operation & $59.62 \pm 4.43$ & $56.84 \pm 4.24$ & 3.069 & 0.003 \\
\hline & $\mathrm{t}$ value & 0.719 & 4.658 & & \\
\hline & P-value & 0.474 & $<0.001$ & & \\
\hline
\end{tabular}

retrospectively analyzed. All the patients underwent successful resection of tumor tissue for the first time, and preoperative evaluation showed that they could be performed preventive stoma reversion. Forty-four patients, including 26 males and 18 females, were treated with routine nursing as control group; 48 patients, including 32 males and 16 females, were treated with early nutritional support and nursing intervention (including stomal nursing and perioral dermatitis nursing) as experimental group. There was no significant difference in general information between the two groups $(\mathrm{P}>0.05)$. All patients were diagnosed with rectal cancer by imaging and fiberoptic colonoscopy and pathological tissue test before operation, and low rectal cancer was diagnosed by rectal examination. All patients were excluded from Hartmanton, TEM, McB, temporary or permanent colostomy, local anal resection, cardio-cerebrovascular disease, diabetes, anemia, hypoproteinemia and other diseases.

This study was approved by the Medical Ethics Committee of the The Sixth Affiliated Hospital of Sun Yat-Sen University and informed consent was signed by the patients and their families (Table I).

Nursing methods. The patients in the control group received nursing intervention, including routine nursing, diet nursing, symptom nursing and other preoperative nursing care before operation, as well as routine nursing, psychological nursing, 
A

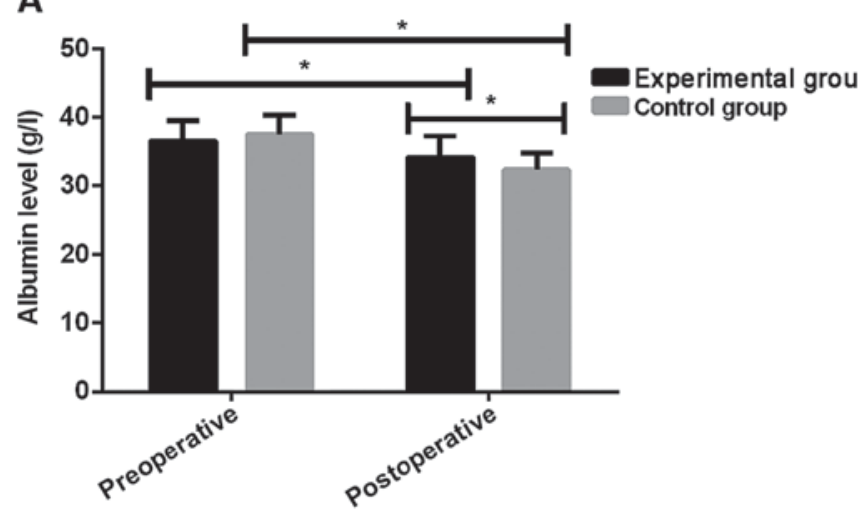

B

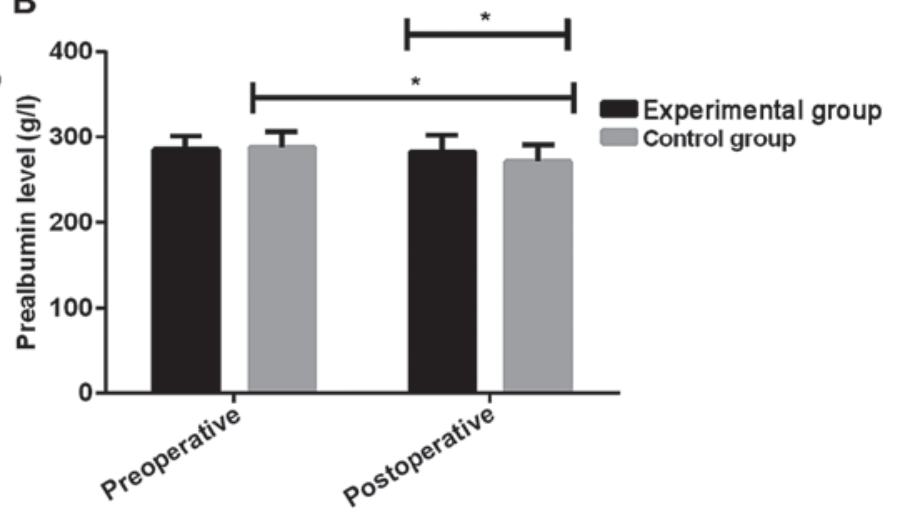

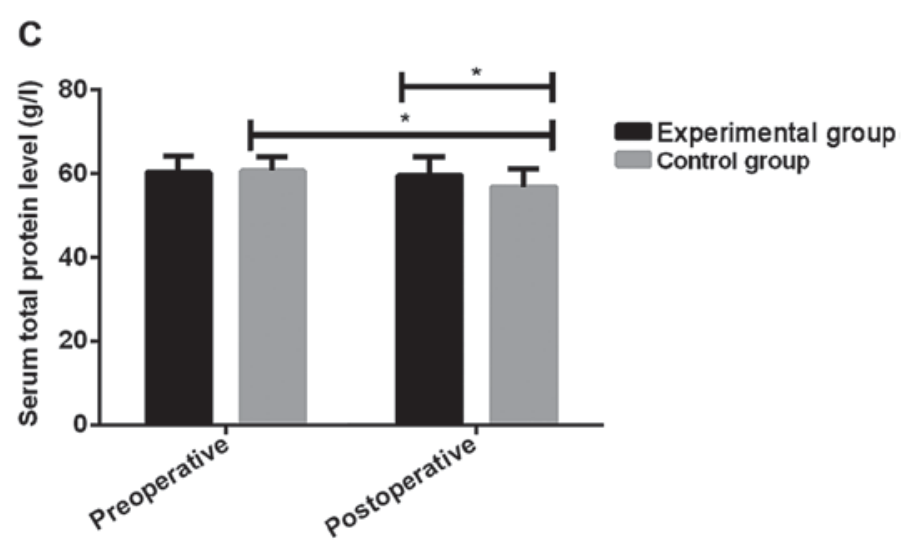

Figure 1. Comparison of nutritional status. The results showed that (A) the level of albumin in the experimental group after operation was significantly higher than that in the control group, and the difference was statistically significant $(\mathrm{P}<0.05)$; the levels of albumin in the two groups after operation were significantly lower than those before operation, and the difference was statistically significant $(\mathrm{P}<0.001)$; the level of albumin in the control group after operation was significantly lower than that before operation, and the difference was statistically significant $(\mathrm{P}<0.001)$. (B) The level of prealbumin in the experimental group after operation was significantly higher than that in the control group, and the difference was statistically significant ( $<<0.05)$; the level of prealbumin in the control group after operation was significantly lower than that before operation, and the difference was statistically significant $(\mathrm{P}<0.001)$. (C) The level of serum total protein in the experimental group after operation was significantly higher than that in the control group, and the difference was statistically significant $(\mathrm{P}<0.05)$; the level of serum total protein in the control group after operation was significantly lower than that before operation, and the difference was statistically significant $(\mathrm{P}<0.001){ }^{*} \mathrm{P}<0.05$.

diet nursing, symptom nursing, posture nursing, pipeline nursing and other postoperative nursing care after operation and health education (10).

The patients in the experimental group received early nutritional support combined with nursing intervention. The specific methods are as follows: The patients in experimental group were treated with enteral nutritional emulsion (Sino-Swed Pharmaceutical. Corp. Ltd., Beijing, China; SFDA approval no. H20040188) for nutritional intervention within 6-24 h after operation, 1,000 $\mathrm{ml}$ daily, for 7 consecutive days (11).

Observation index. The morning fasting nutritional status (albumin, prealbumin, serum total protein), selfrating anxiety scale (SAS) and self rating depression scale (SDS) were compared between the two groups 1 day before operation and 7 days after operation. The higher the score of both scales, the more serious the depression. The incidence of postoperative adverse reactions, wound infection rate, shaped and regular defecation were analyzed in both groups.

Statistical analysis. The statistical analysis was conducted by SPSS19.0 (IBM Corp., Armonk, NY, USA) statistical software.
Enumeration data were represented by [n (\%)]; $\chi^{2}$ test was used to compare the rate. Measurement data are represented by mean \pm SD. t-test was used for the comparison between the two groups. Paired t-test was used to compare the preoperative and postoperative results in the group. ANOVA was used for comparison beween multiple groups with Dunnett's post hoc test. $\mathrm{P}<0.05$ had statistical significance.

\section{Results}

Comparison of nutritional status. There was no significant difference in the levels of albumin, prealbumin and serum total protein between the experimental group and the control group before operation $(\mathrm{P}>0.05)$. The levels of albumin, prealbumin and serum total protein in the experimental group were significantly higher than those in the control group after operation, and the difference was statistically significant $(\mathrm{P}<0.05)$; the levels of albumin in the two groups after operation were significantly lower than those before operation, and the difference was statistically significant $(\mathrm{P}<0.001)$; there was no significant difference in prealbumin or serum total protein levels before and after operation in the experimental group $(\mathrm{P}>0.05)$. The levels of prealbumin and serum total protein 

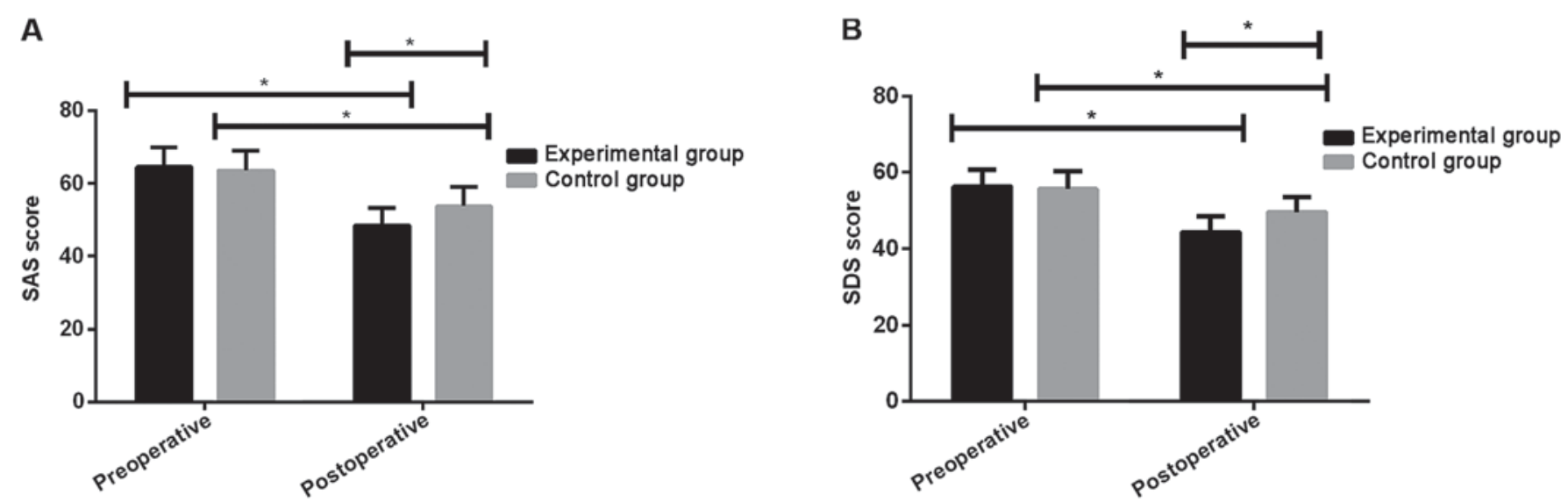

Figure 2. Comparison of psychological status. The results showed that (A) the SAS score in the experimental group after operation was significantly lower than that in the control group, and the difference was statistically significant $(\mathrm{P}<0.001)$; the SAS scores in the two groups after operation were significantly lower than those before operation, and the difference was statistically significant $(\mathrm{P}<0.001)$. (B) The SDS score in the experimental group after operation was significantly lower than that in the control group, and the difference was statistically significant $(\mathrm{P}<0.001)$; the SDS scores in the two groups after operation were significantly lower than those before operation, and the difference was statistically significant $(\mathrm{P}<0.001)$. ${ }^{*} \mathrm{P}<0.001$.

Table III. Comparison of psychological status.

\begin{tabular}{llccrr}
\hline Index & \multicolumn{1}{c}{ Time } & Experimental group $(\mathrm{n}=48)$ & Control group $(\mathrm{n}=44)$ & $\mathrm{t}$ value & P-value \\
\hline SAS & Before operation & $64.52 \pm 5.34$ & $63.58 \pm 5.53$ & 0.829 & 0.409 \\
& After operation & $48.53 \pm 4.79$ & $53.74 \pm 5.24$ & 4.983 & $<0.001$ \\
& t value & 15.070 & 8.568 & & \\
& P-value & $<0.001$ & $<0.001$ & & 0.504 \\
\multirow{2}{*}{ SDS } & Before operation & $56.31 \pm 4.38$ & $55.68 \pm 4.62$ & 0.671 & $<0.001$ \\
& After operation & $44.28 \pm 4.31$ & $49.58 \pm 4.06$ & 6.057 & \\
& t value & 13.560 & 6.579 & & \\
& P-value & $<0.001$ & $<0.001$ & & \\
\hline
\end{tabular}

after operation in control group were significantly lower than those before operation, and the difference was statistically significant $(\mathrm{P}<0.001)$ (Fig. 1 and Table II).

Comparison of psychological status. There was no significant difference in SAS and SDS scores between the experimental group and the control group before operation $(\mathrm{P}>0.05)$. The scores of SAS and SDS in the experimental group after operation were significantly lower than those in the control group, and the difference was statistically significant $(\mathrm{P}<0.001)$. The scores of SAS and SDS in the two groups after operation were significantly lower than those before operation, and the difference was statistically significant $(\mathrm{P}<0.001)$ (Fig. 2 and Table III).

Comparison of postoperative adverse reactions, incidence of complications and the number of regular defecation. There was no significant difference between the two groups in the number of nausea, vomiting and pulmonary infection $(\mathrm{P}>0.05)$. The number of abdominal pain, abdominal distention, diarrhea, incision infection and abdominal infection in the experimental group were less than those in the control group, and the difference was statistically significant $(\mathrm{P}<0.05)$. There was no anastomotic fistula in the experimental group or the control group. The number of shaped and regular defecation cases in the experimental group was more than that in the control group, and the difference was statistically significant $(\mathrm{P}<0.05)$ (Table IV).

\section{Discussion}

At present, the performing of preventive stoma for low rectal cancer is to avoid the occurrence of anastomotic fistula in clinic $(12,13)$. Preventive stoma needs reversion operation, at the same time, the recovery of the patient is closely related to whether the operation can be carried out smoothly or not. While reversion operation is also prone to incision, abdominal cavity, pulmonary infection and other complications, all of which would bring great psychological pressure and inconvenient for the patient (14). According to literature reports, the advantages of nursing intervention are mainly reflected in the nursing of patients' wounds and psychological guidance, which can make the patients' physical function recover quickly, and reduce or even totally alleviate of the psychological burden (15). Early nutritional support can effectively improve hormone imbalance, reduce the incidence of postoperative infection, activate the intestinal endocrine system, and promote the recovery of anorectal function (16). 
Table IV. Comparison of postoperative adverse reactions, incidence of complications and the number of regular defecation between the two groups.

\begin{tabular}{lccccccc}
\hline & $\begin{array}{c}\text { Nausea } \\
\text { and } \\
\text { vomiting }\end{array}$ & $\begin{array}{c}\text { Abdominal } \\
\text { pain and } \\
\text { distention }\end{array}$ & Diarrhea & $\begin{array}{c}\text { Incision } \\
\text { infection }\end{array}$ & $\begin{array}{c}\text { Pulmonary } \\
\text { infection }\end{array}$ & $\begin{array}{c}\text { Abdominal } \\
\text { infection }\end{array}$ & $\begin{array}{c}\text { Shaped } \\
\text { and regular } \\
\text { defecation }\end{array}$ \\
\hline Experimental group $(\mathrm{n}=48)$ & $1(2.08)$ & $4(8.33)$ & $2(4.17)$ & $3(6.25)$ & 0 & $2(4.17)$ & $46(95.83)$ \\
Control group (n=44) & $3(6.82)$ & $12(27.27)$ & $8(18.18)$ & $10(22.73)$ & $1(2.27)$ & $9(20.45)$ & $35(79.55)$ \\
$\chi^{2}$ value & 1.238 & 5.732 & 4.654 & 5.137 & 1.103 & 5.785 & 5.785 \\
P-value & 0.346 & 0.026 & 0.044 & 0.035 & 0.478 & 0.023 & 0.023 \\
\hline
\end{tabular}

A retrospective analysis of 92 cases of patients with low rectal cancer undergoing preventive stoma reversion was conducted, the levels of albumin, prealbumin, serum total protein, SAS and SDS scores in both groups 1 day before and 7 days after operation were compared, and the incidence of postoperative adverse reactions, wound infection rate, shaped and regular defecation were analyzed. The results showed that the levels of albumin, prealbumin and serum total protein in the experimental group were significantly higher than those in the control group after operation, and the difference was statistically significant $(\mathrm{P}<0.05)$. The levels of albumin in the two groups after operation were significantly lower than those before operation, and the difference was statistically significant $(\mathrm{P}<0.001)$. The levels of prealbumin and serum total protein in the control group after operation were significantly lower than those before operation, and the difference was statistically significant $(\mathrm{P}<0.001)$. This result showed that the nutritional level of the experimental group was superior to that of the control group at 7 days after operation. However, surgery could promote catabolism, reduce the nutritional status of patients, thereby reducing immunity and increasing the possibility of postoperative complications (17). This study found that the SAS and SDS scores in the experimental group were significantly lower than those in the control group after operation, and the difference was statistically significant $(\mathrm{P}<0.001)$; the SAS and SDS scores in the two groups after operation were significantly lower than those before operation, and the difference was statistically significant $(\mathrm{P}<0.001)$. The tension and anxiety of patients due to adverse reactions that might occur after operation can be relived by nursing intervention combined with early nutritional support, which could help patients' psychology, reduce negative emotions, and effectively alleviate their anxiety $(18,19)$. According to literature reports, adverse reactions of early nutritional support were mainly characterized by nausea and vomiting, abdominal pain and abdominal distension, diarrhea and other symptoms (20). In this study, there was no significant difference between the two groups in the number of nausea, vomiting and pulmonary infection ( $\mathrm{P}>0.05)$; the number of abdominal pain, abdominal distention, diarrhea, incision infection and abdominal infection in the experimental group were less than those in the control group, and the difference was statistically significant $(\mathrm{P}<0.05)$. There was no anastomotic fistula in the experimental group or the control group. The number of shaped and regular defecation cases in the experimental group was more than that in the control group, and the difference was statistically significant
$(\mathrm{P}<0.05)$. It might be that early nutritional support could cause the hepatic portal venous system to absorb nutrients, thus facilitating the absorption of the nutrient substrate in the small intestinal mucosa and maintaining the barrier function of the intestinal mucosa. The incidence of intestinal infection and adverse reactions could also be reduced effectively to avoid intestinal stress reaction (21).

In conclusion, early nutritional support combined with nursing intervention can improve the nutritional status, psychological anxiety-depression of the patients undergoing preventive stoma reversion, and effectively decrease the incidence of adverse reactions, and wound infection rate. It can also increase the shaped and regular defecation cases and is helpful for the recovery of intestinal function.

\section{Acknowledgements}

Not applicable.

\section{Funding}

This study was supported by Guangdong Provincial Science and Technology Program (2014A020212716).

\section{Availability of data and materials}

The datasets used and/or analyzed during the current study are available from the corresponding author on reasonable request.

\section{Authors' contributions}

$\mathrm{XY}$ and DH conceived the study and drafted the manuscript. $\mathrm{JZ}$ and YL acquired the data. QY and HW analyzed the data and revised the manuscript. All authors read and approved the final manuscript.

\section{Ethics approval and consent to participate}

This study was approved by the Ethics Committee of The Sixth Affiliated Hospital of Sun Yat-Sen University (Guangzhou, China) and informed consent was signed by the patients and their families.

\section{Patient consent for publication}

Not applicable. 


\section{Competing interests}

The authors declare that they have no competing interests.

\section{References}

1. Sung JJ, Lau JY, Goh KL and Leung WK; Asia Pacific Working Group on Colorectal Cancer: Increasing incidence of colorectal cancer in Asia: Implications for screening. Lancet Oncol 6: 871-876, 2005.

2. Beets-Tan RG: MRI in rectal cancer: The T stage and circumferential resection margin. Colorectal Dis 5: 392-395, 2003.

3. Yamada K, Ogata S, Saiki Y, Fukunaga M, Tsuji Y and Takano M: Long-term results of intersphincteric resection for low rectal cancer. Dis Colon Rectum 52: 1065-1071, 2009.

4. Williams NS: The rationale for preservation of the anal sphincter in patients with low rectal cancer. Br J Surg 71: 575-581, 1984.

5. Lee L, Saleem A, Landry T, Latimer E, Chaudhury P and Feldman LS: Cost effectiveness of mesh prophylaxis to prevent parastomal hernia in patients undergoing permanent colostomy for rectal cancer. J Am Coll Surg 218: 82-91, 2014.

6. Chen Y, Liu BL, Shang B, Chen AS, Liu SQ, Sun W, Yin HZ, Yin JQ and Su Q: Nutrition support in surgical patients with colorectal cancer. World J Gastroenterol 17: 1779-1786, 2011.

7. Hasenboehler E, Williams A, Leinhase I, Morgan SJ, Smith WR, Moore EE and Stahel PF: Metabolic changes after polytrauma: An imperative for early nutritional support. World J Emerg Surg 1:29, 2006.

8. Finlayson E, Zhao S and Varma MG: Outcomes after rectal cancer surgery in elderly nursing home residents. Dis Colon Rectum 55: 1229-1235, 2012.

9. Cole S and Branagan G: Rectal cancer management and high levels of anxiety and depression. Surgeon 10: 303, 2012

10. Gentile M, Bucci L, Cerbone D, D'Antonio D and Guarino V: Evaluation of downstaging as leading concept in sphincter-saving surgery for rectal cancer after preoperative radio-chemotherapy (Preop RCT). Ann Ital Chir 74: 555-558, 2003.

11. Männistö S, Yaun SS, Hunter DJ, Spiegelman D, Adami HO, Albanes D, van den Brandt PA, Buring JE, Cerhan JR, Colditz GA, et al: Dietary carotenoids and risk of colorectal cancer in a pooled analysis of 11 cohort studies. Am J Epidemiol 165: 246-255, 2007.

12. Wang S, Wang W, Zhu B, Song G and Jiang C: Efficacy of prophylactic mesh in end-colostomy construction: A systematic review and meta-analysis of randomized controlled trials. World J Surg 40: 2528-2536, 2016.
13. Yoo SB, Jeong SY, Lim SB, Park JW, Choi HS and Oh JH: Left-sided ileostomy at specimen extraction site in laparoscopicassisted low anterior resection for rectal cancer. J Laparoendose Adv Surg Tech A 23: 22-25, 2013.

14. Lee WS, Lee WY, Chun HK, Yun SH, Cho YB and Yun HR: Curved cutter stapler vs. linear stapler in rectal cancer surgery: A pilot prospective randomized study. Int J Colorectal Dis 24 : 1327-1332, 2009.

15. Serpentini S, Del Bianco P, Alducci E, Toppan P, Ferretti F, Folin M, De Salvo GL, Nitti D and Pucciarelli S: Psychological well-being outcomes in disease-free survivors of mid-low rectal cancer following curative surgery. Psychooncology 20: 706-714, 2011.

16. Pischon T, Lahmann PH, Boeing H, Friedenreich C, Norat $\mathrm{T}$, Tjønneland A, Halkjaer J, Overvad K, Clavel-Chapelon F, Boutron-Ruault MC, et al: Body size and risk of colon and rectal cancer in the European Prospective Investigation Into Cancer and Nutrition (EPIC). J Natl Cancer Inst 98: 920-931, 2006.

17. Liang Z, Ding W, Chen W, Wang Z, Du P and Cui L: Therapeutic evaluation of biofeedback therapy in the treatment of anterior resection syndrome after sphincter-saving surgery for rectal cancer. Clin Colorectal Cancer 15: e101-e107, 2016.

18. Néron S, Perez S, Benc R, Bellman A, Rosberger Z and Vuong T: The experience of pain and anxiety in rectal cancer patients during high-dose-rate brachytherapy. Curr Oncol 21: e89-e95, 2014.

19. Koscielny S and Gottschall R: Perforation of the hypopharynx as a rare life-threatening complication of endotracheal intubation. Anaesthesist 55: 45-52, 2006 (In German).

20. Boelens PG, Heesakkers FF, Luyer MD, van Barneveld KW, de Hingh IH, Nieuwenhuijzen GA, Roos AN and Rutten HJ: Reduction of postoperative ileus by early enteral nutrition in patients undergoing major rectal surgery: Prospective, randomized, controlled trial. Ann Surg 259: 649-655, 2014.

21. Yang H, Feng Y, Sun X and Teitelbaum DH: Enteral versus parenteral nutrition: Effect on intestinal barrier function. Ann NY Acad Sci 1165: 338-346, 2009.

This work is licensed under a Creative Commons Attribution-NonCommercial-NoDerivatives 4.0 International (CC BY-NC-ND 4.0) License. 